\title{
Communicative Language Teaching: A Practical Scenario in the Context of Bangladesh
}

\author{
Md. Kawser Ahmed \\ Department of English, Z.H. Sikder University of Science \& Technology, Madhupur, Kartikpur, Bhedergonj, Shariatpur, Bangladesh \\ E-mail: kawser.zhsust@gmail.com
}

Doi:10.7575/aiac.alls.v.7n.5p.97

URL: http://dx.doi.org/10.7575/aiac.alls.v.7n.5p.97
Received: 21/05/2016

Accepted: 02/08/2016

\begin{abstract}
Communicative Language Teaching, popularly known as CLT, has become a newly adopted methodology in the teaching and learning context of Bangladesh. This methodology, since the initiation, has encountered and is still encountering a number of hurdles that need to be dealt with best care and feasible strategy. Of all methods, most of the educational institutes be- it secondary or higher secondary are inclined to accept and apply the CLT in classroom, though there has been a lack of resources, materials and language experts. Ignoring the reality, the policy makers would like to follow the other countries, though they are self-sufficient and self-dependent on their strategic plans and strong funds who have already executed CLT with success. This paper attempts to present the reality behind the implementation of CLT in the language teaching and learning environment and outlines the malpractices widely obvious in educational institutes of Bangladesh. This paper also focuses on the strategic points, data collection and analysis and probable remedy regarding the real picture of CLT in Bangladesh.
\end{abstract}

Keywords: CLT, methodology, context, hurdles, Bangladesh

\section{Introduction}

Teaching English in educational institutes of Bangladesh bears the testimony of the traditional Grammar Translation Method where deductive application of grammatical rules and translation from target language to native one is encouraged. This happens not only in rural environment, as there has been a great lack of skilled teachers, practitioners and trainers, but also in reputed schools and colleges of Bangladesh where teachers are no longer interested to apply this methodology, Communicative Language Teaching (CLT), because of not having strict policies from the government and institute. Rather it is frequently seen that they remain busy with their private tuitions and other monetary affairs related activities, though many of them receive training and participate in seminars and conferences on how to apply CLT and other effective methodology to dispense English language teaching. This paper, in fact, focuses on why the teachers are on longer interested and do not apply the CLT in teaching and learning environment effectively. Similarly, research findings of this paper highlight the pitfalls of teaching methodologies that are practiced in the name of Communicative Language Teaching (CLT) and the survey work taken from different educational institutes with numerous questions at secondary and higher secondary level. It is, however, relevant to mention that no specific methodology is applied up to primary level teaching in Bangladesh and some rhymes, vocabularies and sentence completions are done even these are not done on regular basis. Rather students are encouraged to memorize set rules and thus apply them in examination.

\section{What is Communicative Language Teaching (CLT)?}

Communicative Language Teaching (CLT) is an approach in the teaching arena of second and foreign language where a good communication and interaction among learners is done appropriately outside of the classroom. This communication is based upon everyday use, social necessary, formal invitation and classroom setting and this type of activity is interaction based where learners will not face any communication barrier and present them before others naturally and spontaneously. In fact, this type of communication or interaction is the core objective of CLT. The educators, language experts and language trainers were dissatisfied with the characteristics, applications and modes of teaching-learning of previously used methodologies like Grammar translation Method, Situational Method and Audio lingual Method. They deeply thought over the matters genuinely how a method could have specific and successful goal for communication. It is true to admit students have good competency and mastery over grammatical structures and they have good writing skill on scripts as they are trained to learn by heart some paragraphs and compositions.

It is a pity that most of the students get stumbled when they are asked to make sentences on particular topic or deliver a presentation in front of classmates or unknown crowd, they feel fear and start trembling because they do not have real life experience in communication. What Widdowson, cited in Larsen-Freeman, p. 121, 2000, told in this context is, "being able to communicate required more than mastering linguistics structures. Students may know the rules of linguistic usage, but be unable to use the language." It is understood that communication or interaction requires smooth function of language use usually in society or in formal occasions. Wilkins (1976), cited in Larsen-Freeman, p. 121, 
2000 , told, "It became clear that communication required that students perform certain functions as well, such as promising, inviting, and declining invitations within a social context." Hymes (1971) emphasized on communicative competence than linguistic competence because linguistic competence focuses on rules, structures and drills of language. On the other hand, communicative competence refers to the functional use of language in any stage of communication knowing exactly when and how a person makes an interaction on specific topic with the person expected to make response in respect to the questions made. "Communicative Language Teaching aims broadly to apply the theoretical perspective of the Communicative Approach by making communicative competence the goal of language teaching and by acknowledging the interdependence of language and communication" (Larsen-Freeman, p. 121, 2000). The teacher plays a vital role in CLT as he/she offers a situation in which learners will participate in writing and speaking activity-be it in pair work or group work. Learners will make a discussion with each other on the topic given by the teacher and they will present individually what they have worked out. Teacher does not remain silent rather he/she will monitor students' attempts to the task, guide them for mutual discussion and debate and finally ask them for response or presentation of the ideas they have obtained. A number of principles by Richards and Rodgers (2000:161) related to CLT theory are relevant to mention here.

1. The communication principle: Activities that involve real communication promote learning

2. The task principle: Activities in which language is used for carrying out meaningful tasks promote learning

3. The meaningfulness principle: Language that is meaningful to the learner supports the learning process.

In fact, CLT focuses on teachers' facilitation in teaching, students' active involvement in learning and the sufficiency of instrumental and technological aids in classroom environment. However, CLT will encounter a number of challenges because of its usability and acceptability irrespective of region, economy and culture.

\section{The Application of Communicative Language Teaching in Bangladesh: A Perspective Discussion}

It can be said without any doubt that Bangladesh has had the prevalence of different streams of education, for example, Bengali medium, English medium, Madrasa education and other medium where discrete teaching-learning of English has been noticed for long time. Under these different streams, specific application of appropriate method like Communicative Language Teaching (CLT) is very difficult as there are no definite guidelines from the authority. If we look at Bengali medium schools and colleges, it will be obvious that CLT is hardly used because of a number of reasons such as up to date materials, skilled teachers and technological aids. Besides these, syllabus and curriculum pattern do not match with the criteria of CLT because there has been a wide application of traditional contents in those syllabuses. Alam (2007) writes, "English was the medium of instruction and....Bengali was taught extremely inadequately and rather half-heartedly" (p.373). In that case, Bengali was taught without teachers who greatly use deductive application of the Grammar-Translation Method and students feel comfortable about the multiple choice questions (MCQ), grammatical questions and composition writing. All of the questions and answers are prepared by the teachers for the benefit of the students and students entirely depend much on the assistance of teachers to pass the staircases of examination.

Besides, the government has shown much passion towards Bengali language than English since the independence of Bangladesh. The dominance of English language outside of the classroom has been diminishing gradually and the teaching and learning system has been done in Bengali language. The more use of Bengali language in government offices, press releases and public notifications keeps the slow pace of English language in implementation. It is also pathetic to learn that most of the renowned persons and celebrities do not like to apply English in various circumstances like advertisements, banners, festoons and notices. Under these circumstances, English language is getting limited to its wide use of dimension and application. At the end the twentieth century emerged the Communicative Language Teaching (CLT) when there was a great popularity of Grammar-Translation Method (GTM) among teachers and learners. The GT Method worked much in the field of grammar, passage translation, fill in the blanks and for all of the drill based activities, students needed to memorize some grammatical rules, prescribed vocabulary and routinely practice. CLT has made a huge change in the textbooks, course outlines, materials and overall road to English language teaching in the context of Bangladesh. Begum and Nazua say to promote CLT in Bangladesh, the English Language Teaching Improvement Project (ELTIP) was launched in 1997. The Government of Bangladesh and the Government of the UK jointly funded this teacher improvement project (p.91). To try and ensure a CLT-friendly teaching-learning situation, this project focused on "three main areas: teaching materials, teacher training and the reformation of the examination system" (Yasmin, 2006, p. 137). In the teaching of English, a popular but common book namely English for Today has been introduced maintaining all of the criteria of CLT. The book, although it has a number of limitations, has become handy in the context of CLT and the experts have designed this book with up to date information and in detail description. "The problem of Communicative Language Teaching (CLT) is that the term has always meant a multitude of different things to different people", Jeremy Harmer (2003). Language experts are anxious about the mode of acceptability of CLT as teachers having insufficient conceptual knowledge and practical training experiences mix up this methodology of teaching with other methodologies. This picture is quite obvious in the English language teaching arena of Bangladesh and students learn English grammar, set rules and composition in a traditional way. Under the budget of different governments and monitor work, teachers across the country have been trained up to make the teachers acquaint with the principles of CLT by ELTIP. “....it is hard to see how top-down policy changes to textbook or methodology will change outcomes, as the poor and disadvantaged students, most of whom reside in rural Bangladesh, will be unable to take advantage of such innovation to develop competence in the language" Hamid and Baldauf (2008), cited in Approaches and Methods of Language Teaching (2013) by Binoy Barman and Bijoy Lal Basu. 
Literally, though this method has brought some revolutionary changes, it ultimately does not come up with the expectations of teachers. Teachers have considered this method as burden rather than as facilitation and thought it as alien in the teaching and learning of English language. The government, however, is persistent to implement CLT in the mainstream education system of Bangladesh and has modified policies and adopted some pragmatic measures in which CLT would see a good prospect.

\section{Literature Review}

In this section of the paper, I would make a comparative study between what the major works were done and what I will present related to the title of the paper. This paper will initiate some of the experimental discussion along with scholars' views in which the application of CLT and the hurdles dealt with in many of the educational institutes are discussed. First of all, GT Method can be discussed with its characteristic features in the teaching and learning context of Bangladesh. Teachers of Bengali medium schools and colleges feel comfortable to use the deductive method of grammatical analysis and presentation in the classroom. Richards and Rodgers (2001) highlight the goal of GT Method thus: "The goal of foreign language study is to learn a language in order to read its literature or in order to benefit from the mental discipline and intellectual development that result from foreign language study" (p.5).

However, according to Richards and Rodgers (2001) the Audio lingual Method popularly known as the Army Method was initiated to make the personnel understand the language in the period of Second World War in the US. This method was used widely for the purpose of interpretation, code-room assistance and translation. Through the setting up of special language training program, this method worked better, though it had some limitations to a great extent. Moreover, Richards and Rodgers (2001) clarified that the aim of Audio lingual method was to help participants "attain conversational proficiency in a variety of foreign language (p.50)."

In this paper, I would like to clarify the experimental study of CLT in the context of Bangladesh where the hurdles related to the effective application of this method are dealt with data presentation and analysis. In addition, the background information of the introduction of CLT in Bangladeshi education system has been discussed and a comparative study based on different media of schooling has been detailed as well. In fact, the successful implementation of CLT highly depends on the education policy of Bangladeshi government, the up to date training of teachers and trainees in different educational institutes and the communication building up between the institutes of city area and village area. The language teachers and trainers need to come out of traditional roles of teaching in the language learning classroom. Jeremy Harmer, in this regard, points out that under the section of the roles of a teacher who is "one who is democratic rather than autocratic and who fosters learner autonomy through the use of group work and pair work and by acting as more of a resource than a transmitter of knowledge" (The Practice of English Language Teaching, p.108).

In this part of the paper, I have attached the methodology, the results and findings of survey work done in secondary and higher secondary level of education in Bangladesh. This survey work has been conducted highlighting the true picture and the use of CLT in the educational institutes of Bangladesh where full concentration was on the language teaching and learning.

\section{Methodology}

A survey work was conducted on how CLT is utilized in educational institutes especially at school and college education in Bangladesh. Behind the survey work, a set of questionnaire was set up and put forward to the learners who were learning English as a second language. They were given guidelines on how they answered and made comments after reading the questions. Also they were encouraged to feel independent to make comments on what they learned from their teachers and what the teachers did at classroom to apply the method of CLT. Along with the survey work, a formal discussion was done with the language teachers and trainers to understand the practical scenario of CLT in the present situation of Bangladesh. However, the survey work was done spontaneously, not by applying any force to any student to make the report free and open.

\section{Results of the Study}

The survey work was conducted among one hundred students from college level and they were given out the questionnaire with proper explanations for making comments and suggestions.

Question Questions followed by answers based upon survey work are given below.

No.

1. Question: Is CLT appropriately applied in the language learning classroom?

Answer: Of all students, 80 percent students out of 100 percent replied that the CLT has been applied in a proper way. 20 percent students said that they did not see the proper utilization of CLT because it requires the combination of theoretical and practical approach to make the learning effective. The effective use of four skills like Reading, Writing, Listening and Speaking cannot be done in most of the educational institutes of Bangladesh especially for Listening no suitable lab and for Speaking no effective guidelines and practices are followed. 
2. Question: Is there any insufficiency of modern and technological equipment to apply CLT method in Bangladesh?

Answer: Almost 50 percent students out of 100 percent told that they could see nothing effective and relevant use of modern technological aids and equipment were seen during the language teaching and learning environment. For CLT, computer or laptop, overhead power point projector, multimedia and CD/DVD are highly essential. But most of the students at secondary and higher secondary level were dissatisfied about the lack of these instruments and they thought of the necessity of these essential aids for language learning.

3. Question: Which skills have been emphasized in a language learning classroom?

Answer: 70 percent of the students out of 100 percent have admitted that Reading is more emphasized than Listening and Speaking. There is a reason behind this that the third world countries like Bangladesh experience poor socio-economic set up where no implementation of CLT can be done. In fact, most of the educational institutes suffer from weak management, unskilled teachers and trainers.

4. Question: Is there any pair work or group work done in the classroom?

Answer: 60 percent students out of 100 percent say that in language learning classroom, they do not have the scope of any pair work or group work. Students come into the classroom, get the percentage of attendance, read out what their teachers command and follow the traditional style learning. They feel the lack of participation in classwork, case study, presentation before the audience and interactive method of learning.

5. Question: As the goal of CLT is to make the learners independent, is the language learning classroom teacher oriented or learner oriented?

Answer: In the survey work, 80 percent students out of 100 percent report that the teaching-learning activities are teacher oriented and teacher dominates the students and works as a controller in the classroom. Students like the silent observers observe teachers' movements, instructions and do the drills or grammatical works assigned upon them. The learners themselves feel isolated from the mainstream learning and remain passive at the time of class conducted by teachers. A great lack of encouragement from teachers' side is greatly responsible not to make the learners independent.

6. Question: Do the teachers emphasize on pronunciation or oral presentation in language learning classroom?

Answer: Truly speaking, the practical scenario of CLT gets stumbled in the way of accomplishment when there is the concept of practicing oral presentation and pronunciation. The teachers or the language trainers, nearly 70 percent out of 100 percent at school and college levels, do not give emphasis on these essential skills rather they focus on grammar, spelling, paragraph writing and composition works. In this case, the mission of CLT is not fulfilled in most of the educational institutes of Bangladesh.

I have made another study which included university teachers, bureaucrats and administrative officers of the Ministry of Education to get the real picture of the application of CLT. The reasons behind the inclusion of bureaucrats and administrative officers in my study are that Bangladesh is one of the fewest countries where government employees play a great role in designing, revising and fixing the syllabus conniving at the role of language experts and teachers. I have included three different but identical questions to the respective individuals (university teachers, bureaucrats and administrative officers).

These questions are as follows:

Question Questions followed by answers based upon survey work are given below.

no

Question:

Do you think that the fixation of CLT is relevant in the cultural and economic strata of Bangladesh?

Answers:

University teachers say that as CLT is the replacement of traditional teaching method in Bangladesh, it is facing a number of problems. For instance, the government does not have enough funds to train up teachers in the mode of CLT. So it can be understood that teachers are quite doubtful about the fixation and implementation of CLT and they think 40 percent relevancy goes with the culture and economy of Bangladesh. On the other hand, bureaucrats and administrative officers are positive to the new teaching methodology and they make their argument that the learners need to go with the stream of modern education like other developed countries. According to bureaucrats and administrative officers, 60 percent will be successful and bring about a positive change in the realm of education. 


\section{Percentage of relevancy for CLT in Bangladest}

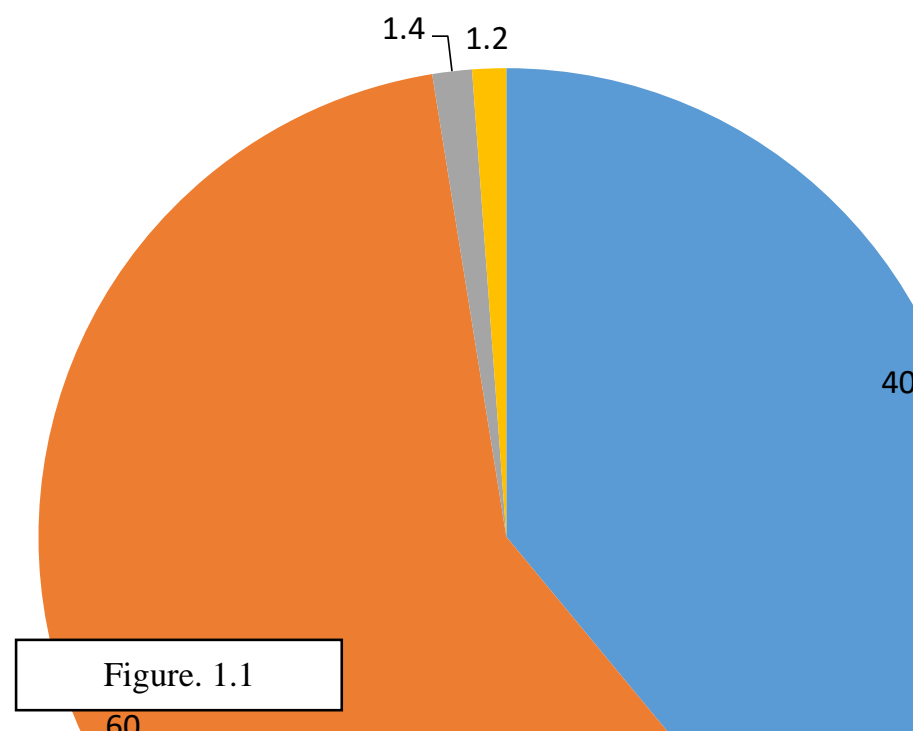

Whether it is relevant or irrelevant, how will this methodology be implemented effectively?

\section{Answer:}

University teachers unanimously opine that the efficacy of CLT will rely much on the research work, feasibility study and suggestions. They think that 70 percent efficacy of CLT will be implemented successfully as it will undergo a scientific research and relevant survey work. However, bureaucrats and administrative officers consider that such activities like project work, research and suggestions from linguists and experts will ensure only 30 percent progress of this methodology.

\section{Percentage of the implementation of methodology for CLT}

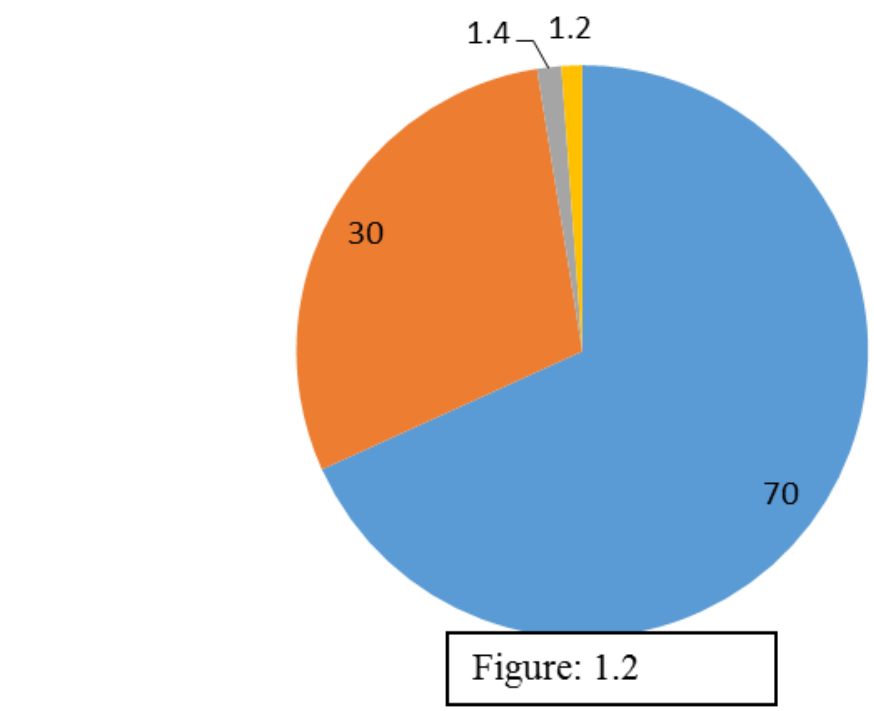

\section{$3 \quad$ Question:}

How much portion of budget needs to be allocated to make CLT appropriate in proportionate to the huge number of students?

\section{Answer:}

University scholars give their opinions strongly that sufficient budget needs to fixed to meet up the needs of growing number of students across the country. As English is a common subject to all students, it can easily claim to have 50 percent monetary allocation of total expenditure for English language teaching each year. Similarly, bureaucrats and administrative officers also express their solidarity in respect of the budget allocated for English language teaching annually. 


\section{Percentage of the budget implementation for CLT}

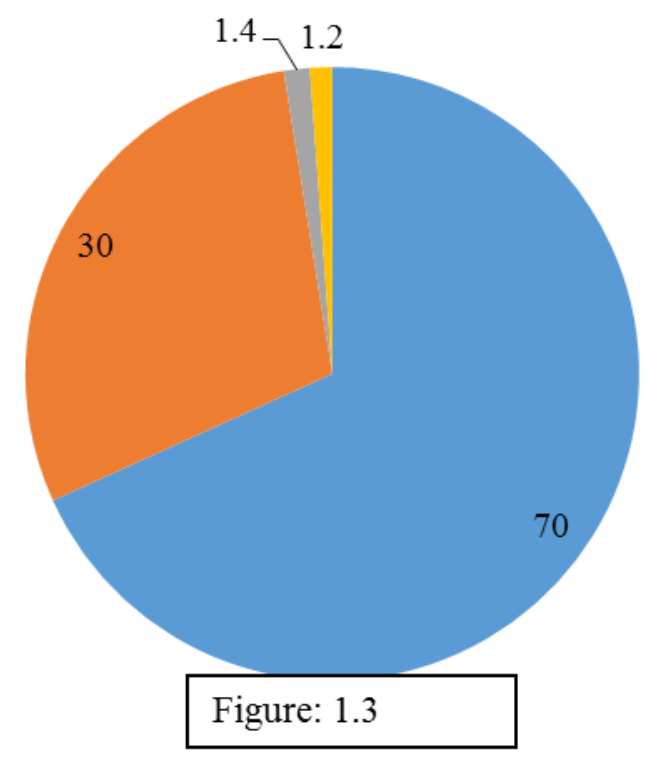

\section{Limitations of the Study}

The application of CLT in the context of Bangladesh does not bear a satisfactory picture especially in the rural areas where no scopes and technological aids are available. The survey shows a practical scenario of CLT that it has encountered a number of limitations as it has not been done in a wide range in associations with private and public educational institutes, most of them include town area only. The survey work would bring about a true picture if it were done in village and marginal educational institutes where opportunities to learn a language are scarce. The teachers remained busy with their scheduled classes and students were run on attending the classes in time. Thus I could not manage much time to talk to them and make an interview on the questionnaire I have prepared. However, it is a matter of pity to learn that a major portion of students are not well familiarized with CLT and its prospective usage in their course curriculum. I have prepared a set of questionnaires to get the answers from teachers and students to complete my survey work successfully, but I have found some difficulties like fixing up time slot of teachers and language trainers, students' confusing answers in response to my questions and, in some cases, busy schedule of school authority to let me allow to conduct the survey work. It would be great if I make a comparative study between Bengali medium and English medium schools about the teaching-learning methodologies. As English medium schools follow modern teaching-learning methodology, then a good picture would be picked up from that type of survey work.

In the second study, the comments of university teachers and government employees have been shown, though in a limited scope. Teachers' comments are quite opposite to that of government bodies and there has been a variation of percentage of data regarding their opinions. The study would be more effective, if I showed the comments of teachers from private and public universities and other respective bureaucrats.

\section{Recommendations}

It is, however, relevant to mention that I have tried to point out the concept of CLT and its practical but true picture in the circumstance of Bangladesh. In this paper, I have tried to pick out some pitfalls on the application of CLT in educational institutes, teachers and trainers' lack of conceptual knowledge and other administrative and logistic supports for the better implementation of this methodology. Following are a number of guidelines presented as recommendations to make the CLT more effective and pragmatic.

\subsection{Application of Interactive Approach to Teaching-Learning}

Ignoring the traditional method of teaching-learning, the teachers need to think over the interaction of learners in which learners will have independency and feel free in classroom drills and works. Teachers can focus on the fluency and accuracy of language to have mastery over four skills especially on speaking skill. "Fluency is developed by creating classroom activities in which students must negotiate meaning, use communication strategies, correct misunderstanding, and work to avoid communication breakdowns" (Jack C. Richards, p.14, 2006). Teachers also should pay attention to communicative activities among students. "Communicative interaction encourages cooperative relationships among students. It gives students an opportunity to work on negotiating meaning" (Diane-Larsen Freeman, p.73, 2004). The interaction between teachers and students should be done in such a way that they will coordinate the students and make the topics easy for them. "...... he is the facilitator of the activities, but he does not always himself interact with the students. Sometimes he is a co-communicator, but more often he establishes situations that prompt communication between and among the students" (Diane-Larsen Freeman, p. 130, 2004) Most importantly, teachers should play a significant role to motivate learners to come out of the old method of learning and facilitate them to understand the topic for further clarification in association with other students. 


\subsection{Limiting the Use of Grammar and Maximizing the Language Skills}

In CLT, the deductive approach of grammar is highly restrained rather the inductive application of grammar is emphasized. Learners are, first of all, taught language drills in pair or group work and then grammar is accomplished in the purposeful way of communication. Learners are instructed to use grammar in describing any drawing or picture and thus they become able to apply them in real life environment.

\subsection{Availability of Administrative and Logistic Supports}

To make CLT effective in Bangladesh, fixation of government policy and adequacy of logistic materials are highly needed. As Bangladesh belongs to third world countries, it has insufficiency of funds and inadequacy of infra-structural limitations. The government cannot afford to provide schools and colleges with modern technological supports like laptops, overhead projectors, multimedia classroom and language lab. Besides, teachers and language trainers are not well-trained to teach students maintaining the basic characteristics of CLT.

In this regard, the administrative body of government, the policy makers of education and the authority of educational institutes must think over this crucial issue in which they can implement CLT in classroom effectively. The government needs to arrange sufficient training programs and collaborates its mode of education with other reputed foreign universities by which they can have memorandum of understanding (MoU) and exchange of views on teaching and learning.

\subsection{Evaluation and Testing Procedure}

Unlike Grammar-Translation Method, CLT focuses on the evaluation and test with the authentic materials. It is not learning by heart methodology, but it provokes learners to give test or write on particular topic in a practical environment. "In order to assess students' writing skill, for example, a teacher might ask them to write a letter to a friend" (Diane-Larsen Freeman, p.132, 2004). Students usually feel fear about public speaking or oral presentation and they always try to avoid this task in academic activities. To facilitate learners, teachers can arrange speaking session for their students once in a week and encourage them to speak in front of crowd. "...... since students learn through interacting, lessons should consist of opportunities to communicate in the target language. In this method, teachers often downplay accuracy and emphasize how students communicate when they speak the target language" (David Nunan, p. 50, 2003). In fact, students need to be motivated in participating language drills and teachers have to fix innovative criteria of evaluating students' performance.

\section{Conclusion}

In order for CLT to survive in the context of educational policy of Bangladesh, the language experts, practitioners, policy makers and stakeholders must work together. The government should not cast aside the precious suggestions of teachers who are well-trained and well acquainted with the authenticity and practicality of CLT and allocate available funds for the appropriate application of this methodology in Bangladesh. The conferences and seminars on CLT will not only ensure its original benefits but the efforts and training programs organized time to time at root level of Bangladesh will also mark the significant progress. It is, however, relevant to think that most of the educational institutes are based in rural and remote area and a major portion of students study in such institutes with less amenities and scopes to the newness in education where the concept of new methodology is emerging on the demand authentic and pragmatic education introduced by language experts and specialists around the world. The committee of education policy and the planners of administrative body of government must understand the true scenario of education especially the teaching and learning method of Bangladesh. Hyper policy and utopian scheme regarding the strong implementation of CLT need to be shunned and the practicable way for this methodology needs to be taken for the greater interest of students who belong to rural set ups of the country. As CLT encourages more real life experiences and less emphasis on the direct use of grammar, the teachers need to understand its real motive because discarding the traditional methods that are practiced for long time may bring about poor impression among the learners and the teachers as well. The push in of CLT in the arena of English language teaching must be done very carefully and more research and project based work may be effective where the monitoring system should be done by the administrative body of government and the specialist board concerned in this field.

\section{References}

Alam, F., Zaman, N., Ahmed, T. (eds). (2001). Revisioning English in Bangladesh. Dhaka. The University Press Limited.

Anthony, E.M. (1963). Approach, method and technique. Oxford: Oxford University Press.

Brown, H. D. (1994). Teaching by Principles: An Interactive Approach to Language Pedagogy. NJ: Prentice Hall.

C. Richards, J. (2006). Communicative Language Teaching Today. Cambridge University Press.

Hamid, M.O, and Baldauf, R.B. (2008). Will CLT bail out the bogged ELT in Banglades English Today, 24(3), 16-24.

Harmer, J. (1991). The Practice of English Language Teaching. Essex: Longman Group UK Ltd.

Larsen-Freeman, D. (2000). Techniques and Principles in Language Teaching. New Delhi: Oxford University Press.

Littlwood, W.T. (1981). Communicative Language Teaching: An Introduction. Cambridge. Cambridge University Press. 
Morris, I. (1968). Teaching Foreign Language Skills. London: Macmillan.

Nunan, D. (2003). Practical English Language Teaching. The McGraw Hill Companies.

Nunan,, D. (1989). Designing Classroom for the Communicative Classroom. Cambridge: Cambridge University Press.

Richards, J.C., and T.S. Rogers. (2001). Approaches and Methods on Language Teaching. Cambridge: Cambridge University Press.

Shahidullah, M., Islam J., Majid, I.A. N., Shams, N. (2011). English for Today. National Curriculum and Textbook Board, Dhaka.

Siddique, R. (2004). CLT: Another Assumed Ideal from the West. The Dhaka University Studies.

Sinha, B.S. (2004). Communicative Language Teaching (CLT) and English for Today: Our Dream vs. Reality. The Arts Faculty Journal, Vol.1, June 2004 Issue.

Sinha, B.S. (2006). Communicative Language Teaching (CLT) and English for Today (EFT). The Arts Faculty Journal, Vol.1.

Yasmin, F. (2006). English Language Teaching in Bangladesh: An Overview. The Dhaka University Studies, 63, 133140 . 